\title{
Argatroban therapy for heparin-induced thrombocytopenia in ICU patients with multiple organ dysfunction syndrome: a retrospective study
}

\author{
Bernd Saugel $^{1^{*}}$, Veit Phillip ${ }^{1}$, Georg Moessmer ${ }^{2}$, Roland M Schmid ${ }^{1}$, Wolfgang Huber ${ }^{1}$
}

\begin{abstract}
Introduction: Heparin-induced thrombocytopenia (HIT) is a serious, prothrombotic, immune-mediated adverse reaction triggered by heparin therapy. When HIT is diagnosed or suspected, heparins should be discontinued, and an alternative, fast-acting, parenteral, nonheparin anticoagulation such as argatroban should be initiated. Limited and inconsistent data exist about dosing of argatroban in intensive care unit (ICU) patients with critical illnesses.

Methods: Retrospective analysis of 12 ICU patients with multiple organ dysfunction syndrome (MODS) treated with argatroban for suspected or diagnosed HIT.

Results: The 12 ICU patients with a mean platelet count of $46,000 \pm 30,310$ had a mean APACHE II score of $26.7 \pm$ 7.8 on ICU admission and a mean SAPS II score of $61.5 \pm 16.3$ on the first day of argatroban administration. A mean argatroban starting dose of $0.32 \pm 0.25 \mu \mathrm{g} / \mathrm{kg} / \mathrm{min}$ ( $\mathrm{min}, 0.04 ; \max , 0.83$ ) was used to achieve activated partial thromboplastin times (aPTTs) $>60 \mathrm{sec}$ or aPTTs of 1.5 to 3 times the baseline aPTT. Adjustment to aPTT required dose reduction in six (50\%) patients. Patients were treated for a mean of $5.5 \pm 3.3$ days. The final mean dose in these critically ill patients was $0.24 \pm 0.16 \mu \mathrm{g} / \mathrm{kg} / \mathrm{min}$, which is about one eighth of the usually recommended dose and even markedly lower than the previously suggested dose for critically ill ICU patients. In all patients, desired levels of anticoagulation were achieved. The mean argatroban dose was significantly lower in patients with hepatic insufficiency compared with patients without hepatic impairment $(0.10 \pm 0.06 \mu \mathrm{g} / \mathrm{kg} / \mathrm{min}$ versus $0.31 \pm 0.14 \mu \mathrm{g} / \mathrm{kg} / \mathrm{min} ; P=0.026)$. The mean argatroban dose was significantly correlated with serum bilirubin $(r=-0.739 ; P=0.006)$.
\end{abstract}

Conclusions: ICU Patients with MODS and HIT can be effectively treated with argatroban. A decrease in the initial dosage is mandatory in this patient population. Further studies are needed to investigate argatroban elimination and dosage adjustments for critically ill patients.

\section{Introduction}

Heparin-induced thrombocytopenia (HIT) is a serious, prothrombotic, immune-mediated adverse reaction triggered by heparin therapy [1]. HIT is more often caused by unfractionated heparin than by low-molecular-weight heparin [2]. In HIT, antibodies of immunoglobulin G class bind to a complex of heparin and platelet factor 4, resulting in platelet activation and excessive thrombin

\footnotetext{
* Correspondence: bernd.saugel@|rz.tu-muenchen.de

${ }^{1}$ II. Medizinische Klinik, Klinikum rechts der Isar der Technischen Universität München, Ismaningerstr. 22, 81675 München, Germany
}

generation, leading to thrombocytopenia, a hypercoagulable state, and often to thrombosis. Unless alternative anticoagulation is initiated, the risk of arterial or venous thromboembolic complications in HIT is about $30 \%$ to $75 \%$ of cases, leading to limb amputations in $10 \%$ to $20 \%$ and to death in $20 \%$ to $30 \%$ of cases [3-6]. If platelet count decreases to $\geq 50 \%$ or thrombosis occurs between day 5 and 14 of heparin therapy, or both, HIT should be suspected [7]. In patients with recent heparin exposure within the previous 100 days, clinically significant HIT antibodies may still circulate and can therefore
C Biomed Central

C 2010 Saugel et al.; licensee BioMed Central Ltd. This is an open access article distributed under the terms of the Creative Commons Attribution License (http://creativecommons.org/licenses/by/2.0), which permits unrestricted use, distribution, and reproduction in any medium, provided the original work is properly cited. 
cause an abrupt decrease in platelet count with restarting of heparin treatment [8].

For laboratory diagnosis of HIT antibodies, antigen assays as well as functional assays (platelet activation) are used, both showing a high sensitivity [7,9].

According to consensus guidelines, when HIT, with or without thrombosis, is diagnosed or strongly suspected, heparins should be immediately discontinued and an alternative, fast-acting, parenteral, nonheparin anticoagulation should be promptly initiated [7]. Three alternative parenteral anticoagulants have been approved for use in HIT: the heparinoid danaparoid and the direct thrombin inhibitors, lepirudin and argatroban.

Argatroban is a synthetic direct thrombin inhibitor, derived from L-arginine, that selectively and reversibly inhibits free and clot-bound thrombin at the catalytic site [10]. Argatroban is predominantly hepatically metabolized [11]. Renal elimination of argatroban is minimal, and pharmacokinetic and pharmacodynamic parameters of argatroban have been demonstrated to be comparable between healthy subjects and non-HIT patients with different degrees of renal insufficiency [11-15]. In addition, argatroban anticoagulation has been used successfully during renal-replacement therapy in patients with and without HIT $[15,16]$. However, recent limited data suggested the consideration of kidney function before initiation of argatroban therapy in HIT $[13,17,18]$.

The recommendation for initial dosing of argatroban in HIT is $2 \mu \mathrm{g} / \mathrm{kg} / \mathrm{min}$, adjusted as needed to achieve activated partial thromboplastin times (aPTTs) of 1.5 to 3 times the patient's baseline aPTT $[5,19]$. To account for the reduction in clearance, the recommended initial dose for patients with hepatic impairment is $0.5 \mu \mathrm{g} / \mathrm{kg} /$ min.

Despite the availability of these recommendations, limited and inconsistent data exist about dosing patterns, efficacy, and safety of argatroban therapy in intensive care unit (ICU) patients with critical illness or multiple organ dysfunction syndrome (MODS). Studies on argatroban therapy in critically ill patients with MODS and suspected or diagnosed HIT are limited to very small case series with conflicting results $[13,14]$. Previous data showed that no argatroban dose adjustment is needed in acutely ill patients [20]. In contrast, recent data indicated that the approved dosing regimens of the direct thrombin inhibitors are too high in critically ill ICU patients, especially with MODS $[14,17,21]$. A commonly suggested starting dose for ICU patients is 0.5 to $1.0 \mu \mathrm{g} / \mathrm{kg} / \mathrm{min}$, with adjustment according to aPTT (target range, 1.5 to 3 times or $\geq 60 \mathrm{sec}$ ) $[13,21,22]$. Further investigations are needed to ensure safe, appropriate dosing guidelines for the use of argatroban in the setting of critically ill ICU patients with HIT.
In our retrospective analysis, we evaluated critically ill ICU patients with MODS treated with argatroban for diagnosed or suspected HIT. The primary objective of this observational analysis was to demonstrate dosingadjustment difficulties of argatroban, especially in the setting of MODS.

\section{Materials and methods}

We retrospectively analyzed argatroban dosing patterns and anticoagulant responses in 12 consecutively selected adult patients with MODS who received argatroban for suspected or diagnosed HIT between March 2007 and March 2009 at the general ICU of a German university hospital (Klinikum rechts der Isar der Technischen Universität München, Munich, Germany). The patients were critically ill (defined as having an Acute Physiology and Chronic Health Evaluation II Score, APACHE II, higher than 15) and were treated for MODS involving two or more organ systems. The APACHE II score was calculated after admission of a patient to the ICU and, in addition, the Simplified Acute Physiology Score (SAPS II) was calculated on the first day of argatroban administration.

The general policy in our ICU is to stop all sources of heparin and initiate an alternative anticoagulant on reasonable suspicion of HIT. The choice of alternative anticoagulant agent and initial dose is at the discretion of the treating physician. The dose is generally adjusted to achieve aPTTs $>60 \mathrm{sec}$ or aPTTs of 1.5 to 3 times the baseline aPTT. HIT was defined as a decrease in platelet count to $>150 \times 10^{9} / \mathrm{L}$ or by $>50 \%$, starting at least 5 days after initiation of heparin exposure, provided that a more likely cause for the platelet decline has been ruled out. The aPTT was measured about $2 \mathrm{~h}$ after initial argatroban administration, and dose adjustments were made to maintain desired aPTT levels. The aPTT was assessed daily and $4 \mathrm{~h}$ after any dose adjustment. Data extracted from each patient chart included the demographics, previous heparin exposure, organ-failure status, heparin-induced platelet-activation (HIPA) test results (functional assay, platelet activation), each argatroban dose, as well as aPTT and International Normalized Ratio (INR) values.

A seriously reduced level of consciousness, Glasgow coma scale $<12$ (without head injury) or Cook and Palma score $<12$ was defined as cerebral involvement in MODS. Respiratory insufficiency was defined as necessity for noninvasive ventilation or mechanical ventilation. Need for administration of inotropic substances or vasopressors was documented as circulatory failure. A patient was considered to have hepatic insufficiency if the serum aspartate aminotransferase or alanine aminotransferase levels thrice exceeded the upper limit of normal. A patient was considered to have renal 
insufficiency if the creatinine clearance was $<60 \mathrm{~mL} / \mathrm{min}$ or the serum creatinine was $>3.0 \mathrm{mg} / \mathrm{dL}$, or both, or renal replacement therapy was needed.

Descriptive statistical analyses were performed by using Tinn-R statistical software. Results, where applicable, are reported as mean $\pm \mathrm{SD}$. To evaluate factors associated with the individual mean argatroban dose, we performed univariate analysis (Spearman correlation), including serum bilirubin, aspartate aminotransferase, Model of End-Stage Liver Disease (MELD) score, APACHE II score, and serum creatinine. The Wilcoxon test for unpaired measurements was applied to compare the mean argatroban dose in patients with or without hepatic or renal failure, respectively. Statistical significance was defined as a $P$ value of $<0.05$. Factors significantly correlated to the mean argatroban dose were included in a multiple regression analysis (backward selection) regarding the individual mean argatroban dose in a second step. In addition to the factors derived from Spearman correlation, a limited number of factors with high a priori probability of impact on the mean argatroban dose (such as APACHE II score) and markers of hepatic and renal failure were included in the multiple regression analysis. Statistical analysis was performed by using software (SPSS. version 16; SPSS inc., Chicago, IL, USA). The study was approved by the local ethics committee. The need for informed consent was waived for this retrospective analysis of data.

\section{Results}

\section{Patients}

Twelve (eight female and four male) critically ill ICU patients with a mean age of $70.0 \pm 17.3$ years and a mean weight of $69.5 \pm 20.1 \mathrm{~kg}$ were enrolled in this study (Table 1). The mean APACHE II score on ICU admission and the mean SAPS II score on the day of initial argatroban administration were $26.7 \pm 7.8$ and $61.5 \pm 16.3$, respectively. All patients were treated for MODS with an involvement of two or more organ systems (Table 2), and eight (67\%) patients were classified as having sepsis. Mechanical ventilation was needed in $10(83 \%)$ patients, and administration of inotropic substances or vasopressors was necessary in seven (58\%) patients. Renal insufficiency was observed in seven (58\%) patients, and hepatic insufficiency in four (33\%) patients. Five (42\%) patients died during their ICU stay.

\section{Argatroban anticoagulation}

All patients were treated with argatroban anticoagulation for suspected HIT. When argatroban therapy was started, mean thrombocyte count was 46,000 $\pm 30,310$ / $\mu \mathrm{l}$ ( $\min , 9,000 ; \max , 93,000)$ (Table 3). In six (50\%) patients, suspicion of HIT was confirmed by laboratory tests (functional assay, HIPA test). Argatroban anticoagulation in this study was started at a low dose, and no loading dose of argatroban was used: The mean argatroban starting dose was $0.32 \pm 0.25 \mu \mathrm{g} / \mathrm{kg} / \mathrm{min}$ (min, 0.04 $\mu \mathrm{g} / \mathrm{kg} / \mathrm{min}$; $\max , 0.83 \mu \mathrm{g} / \mathrm{kg} / \mathrm{min}$ ) to achieve aPTTs $>60$ sec or aPTTs of 1.5 to 3 times the baseline aPTT. Desired levels of anticoagulation were achieved in all patients. In the critically ill patients in this study, the aPTT was elevated at baseline (median value of $49 \pm 13$ sec) and increased further (median of $66 \pm 18 \mathrm{sec}$ ) by the first assessment after initiating argatroban. In accordance to that, baseline INR values increased from $1.23 \pm$ 0.38 to $1.49 \pm 0.23$ after starting argatroban. Despite the very low starting dose, adjustment to aPTT required dose reduction in six (50\%; one patient with renal and hepatic failure, two patients with renal insufficiency, one patient with hepatic impairment, two patients with

Table 1 Characteristics of patients, demographic parameters

\begin{tabular}{|c|c|c|c|c|c|c|}
\hline Patient number & Sex & APACHE-II score & SAPS-II score & Main diagnosis & ICU survival & Cause of death \\
\hline 1 & $\mathrm{~m}$ & 17 & 42 & Cirrhosis of the liver & - & Pneumonia, sepsis \\
\hline 2 & $f$ & 27 & 69 & Pneumonia, sepsis & + & \\
\hline 3 & $f$ & 31 & 78 & Erysipelas, sepsis & + & \\
\hline 4 & $f$ & 27 & 56 & Liver failure & - & Pneumonia, sepsis \\
\hline 5 & $\mathrm{~m}$ & 22 & 62 & Intracerebral hemorrhage & + & \\
\hline 6 & $f$ & 33 & 73 & Pneumonia, sepsis & - & Peritonitis, sepsis \\
\hline 7 & $\mathrm{~m}$ & 34 & 77 & Pneumonia, sepsis & + & \\
\hline 8 & f & 17 & 44 & Pneumonia, sepsis & + & \\
\hline 9 & $f$ & 34 & 79 & Pneumonia, sepsis & - & Pneumonia, sepsis \\
\hline 10 & $f$ & 40 & 74 & Pulmonary embolism & - & Heart insufficiency \\
\hline 11 & $f$ & 19 & 54 & Retroperitoneal hemorrhage & + & \\
\hline \multirow[t]{2}{*}{12} & $\mathrm{~m}$ & 19 & 30 & Cirrhosis of the liver & + & \\
\hline & $8 \mathrm{f} / 4 \mathrm{~m}$ & $26.7 \pm 7.8$ & $61.5 \pm 16.3$ & & $7+/ 5-$ & \\
\hline
\end{tabular}

Showing sex (m, male; f, female), APACHE II score on ICU admission, SAPS-II score on the day of first argatroban administration, main diagnosis on ICU admission, ICU survival (+, survived; -, died), and cause of death. Data are provided for each patient as mean \pm SD where possible. APACHE II, Acute Physiology and Chronic Health Evaluation II Score; ICU, intensive care unit; SAPS II, Simplified Acute Physiology Score. 
Table 2 Characteristics of patients and organ dysfunction

\begin{tabular}{|c|c|c|c|c|c|c|}
\hline Patient number & CNS involvement & Respiratory insufficiency & Circulatory failure & Renal insufficiency & Hepatic insufficiency & Sepsis \\
\hline 1 & + & - & - & + & + & + \\
\hline 2 & + & + & - & - & - & + \\
\hline 3 & + & + & + & + & - & + \\
\hline 4 & + & + & + & - & + & + \\
\hline 5 & + & + & - & - & - & - \\
\hline 6 & + & + & + & + & - & + \\
\hline 7 & + & + & - & + & - & + \\
\hline 8 & + & + & + & - & - & - \\
\hline 9 & + & + & + & + & + & + \\
\hline 10 & + & + & + & + & - & + \\
\hline 11 & + & + & - & - & - & - \\
\hline 12 & + & - & - & + & + & - \\
\hline Total & 12 & 10 & 6 & 7 & 4 & 8 \\
\hline
\end{tabular}

Showing organ dysfunction and diagnosis of sepsis at the beginning of argatroban therapy. Data are provided for each patient.

Table 3 Argatroban therapy

\begin{tabular}{|c|c|c|c|c|c|c|c|c|c|}
\hline Patient & $\begin{array}{l}\text { HIPA } \\
\text { test }\end{array}$ & $\begin{array}{l}\text { Platelet count } \\
(\times 1,000 / \mu \mathrm{L})\end{array}$ & $\begin{array}{l}\text { INR before } \\
\text { A }\end{array}$ & INR after $A$ & $\begin{array}{l}\text { aPTT before } \\
\text { A (sec) }\end{array}$ & $\begin{array}{l}\text { aPTT after } \\
\text { A (sec) }\end{array}$ & $\begin{array}{l}\text { aPTT mean during } \\
\text { A therapy (sec) }\end{array}$ & $\begin{array}{l}\text { A starting dose } \\
(\mu \mathrm{g} / \mathrm{kg} / \mathrm{min})\end{array}$ & $\begin{array}{l}\text { A mean dose } \\
(\mu \mathrm{g} / \mathrm{kg} / \mathrm{min})\end{array}$ \\
\hline 1 & + & 93 & 1.2 & 1.6 & 44 & 80 & 68.4 & 0.08 & 0.02 \\
\hline 2 & + & 48 & 0.8 & 1.2 & 39 & 62 & 56.3 & 0.48 & 0.48 \\
\hline 3 & - & 18 & 1.1 & 1.6 & 63 & 106 & 88.7 & 0.56 & 0.37 \\
\hline 4 & + & 9 & 2.1 & 1.5 & 79 & 57 & 93.2 & 0.22 & 0.15 \\
\hline 5 & + & 38 & 1.1 & 1.6 & 29 & 51 & 36.4 & 0.04 & 0.14 \\
\hline 6 & - & 31 & 1.0 & 1.0 & 48 & 51 & 60.5 & 0.14 & 0.14 \\
\hline 7 & - & 87 & 1.1 & 1.4 & 46 & 53 & 62.5 & 0.46 & 0.46 \\
\hline 8 & - & 46 & 1.2 & 1.6 & 52 & 87 & 61.3 & 0.83 & 0.30 \\
\hline 9 & - & 19 & 1.9 & 1.9 & 54 & 63 & 63.0 & 0.08 & 0.08 \\
\hline 10 & - & 15 & 1.1 & 1.6 & 58 & 75 & 67.5 & 0.56 & 0.42 \\
\hline 11 & + & 90 & 1.0 & 1.5 & 42 & 56 & 68.5 & 0.22 & 0.20 \\
\hline \multirow[t]{2}{*}{12} & + & 58 & 1.2 & 1.4 & 36 & 47 & 51.5 & 0.14 & 0.14 \\
\hline & $6+/ 6-$ & $46 \pm 30$ & $1.23 \pm 0.38$ & $1.49 \pm 0.23$ & $49 \pm 13$ & $66 \pm 18$ & $64.8 \pm 15.1$ & $0.32 \pm 0.25$ & $0.24 \pm 0.16$ \\
\hline
\end{tabular}

For each patient (pt), HIPA-test results (+, positive, - = negative), platelet count ( $\times 1,000$ per microliter), INR/aPTT values before argatroban therapy, and INR/aPTT values at first assessment after starting argatroban are provided. Mean aPTTs during argatroban therapy, argatroban starting doses, and argatroban mean doses are shown. Data are provided for each patient and as mean \pm SD where possible. A, argatroban; aPTT, activated partial thromboplastin time; HIPA, heparininduced platelet activation; INR, International Normalized Ratio.

neither hepatic nor renal failure). Patients were treated for a mean of $5.5 \pm 3.3$ days (min, 1 day; $\max , 11$ days). The final mean dose in these critically ill ICU patients was $0.24 \pm 0.16 \mu \mathrm{g} / \mathrm{kg} / \mathrm{min}$ ( $\min , 0.02 \mu \mathrm{g} / \mathrm{kg} / \mathrm{min}$; $\max$, $0.48 \mu \mathrm{g} / \mathrm{kg} / \mathrm{min})$.

The mean argatroban dose was significantly different in patients with hepatic insufficiency compared with patients without hepatic impairment $(0.10 \pm 0.06 \mu \mathrm{g} / \mathrm{kg} /$ min versus $0.31 \pm 0.14 \mu \mathrm{g} / \mathrm{kg} / \mathrm{min} ; P=0.026)$. In contrast, no difference was found in mean argatroban dose in patients with or without renal insufficiency $(0.23 \pm$ $0.18 \mu \mathrm{g} / \mathrm{kg} / \mathrm{min}$ versus $0.25 \pm 0.14 \mu \mathrm{g} / \mathrm{kg} / \mathrm{min} ; P=$ $0.530)$.
Univariate analysis demonstrated that the mean argatroban dose was significantly correlated with serum bilirubin $(r=-0.739 ; P=0.006)$ but not with aspartate aminotransferase $(r=-0.321 ; P=0.309)$, MELD score $(r=0.400 ; P=0.600)$, APACHE II score $(r=0.330$; $P=0.295)$ or serum creatinine $(r=-0.198 ; P=0.538)$. Subsequently we performed multiple regression analysis regarding mean argatroban dose, showing that among all analyzed variables (APACHE II, serum creatinine, presence of hepatic insufficiency, presence of renal insufficiency), only the presence of hepatic insufficiency was independently associated with the mean argatroban dose $(r=0.676 ; P=0.016)$. 
No bleeding complications or other adverse events occurred in the patient population of this study during anticoagulation therapy with argatroban. Furthermore, no arterial or venous thromboembolic complications appeared in the 12 patients treated with argatroban.

\section{Discussion}

In critically ill ICU patients, the recognition, diagnosis, and therapy of HIT is very difficult. Thrombocytopenia (mostly due to sepsis or hemodilution) is a very common laboratory finding, occurring in $\sim 30 \%$ to $50 \%$ of patients in the medical ICU [23]. However, the diagnosis of HIT should be based on clinical considerations and treatment should not be delayed, pending laboratory confirmation [3,7]. On suspicion of HIT, all sources of heparin should be eliminated and an alternative anticoagulant must be initiated [7].

Three alternative parenteral anticoagulants have been approved for treatment of HIT: the heparinoid danaparoid and the direct thrombin inhibitors lepirudin and argatroban [5,24-26].

In the special setting of critically ill ICU patients, argatroban has some advantages over lepirudin [14]. Lepirudin is renally cleared and associated with an increased elimination half-life and bleeding risk in renal failure [27]. Argatroban is metabolized hepatically and eliminated in the feces through biliary excretion [11]. Many studies indicated that renal insufficiency does not influence pharmacokinetic or pharmacodynamic parameters of argatroban and that argatroban is well tolerated and provides adequate anticoagulation in patients with renal dysfunction or failure as well as during renal replacement therapy [11-14,16,28-30]. In contrast, recent limited data suggested consideration of kidney function and dose adjustment in HIT therapy with argatroban [13,16-18]. Moreover, the elimination half-life of argatroban (about 39 to $51 \mathrm{~min}$ in healthy subjects) is reduced by $50 \%$ in comparison to lepirudin [11].

Two prospective, multicenter, historical controlled studies and reanalyses of their combined data demonstrated that the use of argatroban resulted in reducing the composite end point of death, amputation, or new thrombosis in HIT patients, with particular benefit in decreasing new thrombosis without increasing bleeding $[5,19]$.

The recommended initial dose of argatroban for the prophylaxis or treatment of thrombosis in HIT is $2 \mu \mathrm{g} /$ $\mathrm{kg} / \mathrm{min}(0.5 \mu \mathrm{g} / \mathrm{kg} / \mathrm{min}$ for patients with hepatic impairment) with following adjustment to aPTTs of 1.5 to 3 times the baseline aPTT $[5,19]$.

Very limited and inconsistent data exist about dosing patterns of argatroban therapy in ICU patients with critical illness $[13,14]$. Some data demonstrate that no dose adjustment is required in argatroban therapy of acutely ill patients [20]. Other data indicate that the pharmacokinetics and clearance of argatroban seem to be substantially altered in critically ill patients $[13,14,17,21,31,32]$. Especially in the setting of sepsis and MODS, hepatic clearance of argatroban may be significantly reduced. Hepatic metabolism in these patients may be influenced by reduced cardiac output, circulatory distributory failure, and/or disseminated intravascular coagulation, resulting in decreased hepatic perfusion. Therefore, some authors suggest an argatroban starting dose for ICU patients of 0.5 to $1.0 \mu \mathrm{g} / \mathrm{kg} / \mathrm{min}[13,21,22]$.

To gain additional knowledge about dosing-adjustment problems in the use of argatroban in the setting of critical illness and HIT, we retrospectively evaluated 12 ICU patients with MODS treated with argatroban. All patients had developed thrombocytopenia after heparin exposure and had argatroban treatment initiated for suspected HIT whether the diagnosis was ultimately confirmed. The patients in this series were critically ill at the time of argatroban initiation (APACHE II score, $26.7 \pm 7.8$; SAPS II score, $61.5 \pm 16.3$ ) and were treated for MODS. All patients had a platelet count $<100,000 / \mu \mathrm{l}$ (mean platelet count at the time of starting argatroban anticoagulation, 46,000 $\pm 30,310 / \mu \mathrm{l})$. The overall clinical status of our patient population was probably more critical compared with those reported previously. Our patients were treated with a median argatroban starting dose of $0.32 \pm 0.25 \mu \mathrm{g} / \mathrm{kg} / \mathrm{min}$. Further dose reduction was needed in $50 \%$ of the patients. The final required median argatroban dose was $0.24 \pm 0.16 \mu \mathrm{g} / \mathrm{kg} / \mathrm{min}$, representing one eighth of the usually recommended dose. Desired levels of anticoagulation were promptly achieved in all patients.

Compared with previous data, the argatroban dose we applied in our MODS patients was markedly lower than the previously suggested dose for ICU patients, probably reflecting the degree of illness in our patients; likely a tendency existed toward targeting the lower end of the therapeutic aPTT range in these very ill patients.

For example, one recent study investigated argatroban treatment in critically ill ICU patients with HIT II and the necessity for continuous renal-replacement therapy [16]. In this study, Link et al. [16] developed recommendations for argatroban dosing during continuous renalreplacement therapy: They used an initial argatroban bolus of $100 \mu \mathrm{g} / \mathrm{kg}$ followed by continuous infusion of argatroban. In contrast, no bolus of argatroban was used in our study to avoid a peak response of anticoagulation with the risk of bleeding complications. The average rate of argatroban in the study of Link et al. was higher compared with our study $(0.70 \mu \mathrm{g} / \mathrm{kg} / \mathrm{min}$ versus $0.24 \mu \mathrm{g} / \mathrm{kg} / \mathrm{min}$ ). Although both studies investigate argatroban treatment in critically ill patients, our study population of patients with MODS is clearly different 
from the patients included in the study of Link et al. In contrast to our study, Link et al. included only patients receiving continuous renal-replacement therapy. Argatroban was applied into the extracorporeal circulation (prefilter injection/infusion). Furthermore, none of the critically ill patients included in the Link study had a previous history of liver disease. Mean SAPS-II score was lower in this study population compared with that in our study (45 versus 61.5 points).

In general, in critically ill patients with MODS therapeutic interventions are a special challenge. Multifactorial changes in drug disposition and effect occur in these patients, resulting from drug/patient, drug/disease, and drug/drug interactions [33]. In particular, the liver as the primary site of biotransformation can be influenced manifestly, and hepatic impairment is associated with decreased systemic clearance and increased elimination half-life of argatroban [11,22].

\section{Conclusions}

The results of our study suggest that patients with MODS and HIT can be effectively treated by using argatroban anticoagulation. A high index of suspicion is required in diagnosing HIT in these complex patients. However, in critically ill patients with MODS, the dosing of argatroban has to be adjusted. These data do not support the current recommendation of 0.5 to $1.0 \mu \mathrm{g} / \mathrm{kg} / \mathrm{min}$ in patients with critical illness as a reasonable, conservative initial dosage of argatroban. To avoid excessive anticoagulation and bleeding complications, argatroban should be initiated at a markedly reduced dose of about one tenth to one eighth of the recommended $2 \mu \mathrm{g} / \mathrm{kg} /$ min in ICU patients with MODS. Because achievement of steady-state anticoagulation will be delayed in this patient population, aPTT must be checked at close intervals after drug initiation or dose change to ensure that the desired level of anticoagulation is achieved. Further studies are needed to investigate argatroban elimination and dosage adjustments for ICU patients with MODS.

\section{Key messages}

- Patients with MODS and HIT can be effectively treated by using argatroban anticoagulation.

- In critically ill patients with MODS, the dosing of argatroban has to be adjusted.

- To avoid excessive anticoagulation and bleeding complications, argatroban should be initiated at a markedly reduced dose.

\section{Abbreviations}

APACHE II: Acute Physiology and Chronic Health Evaluation II Score; aPTT: activated partial thromboplastin time; HIPA: heparin-induced platelet activation; HIT: heparin-induced thrombocytopenia; ICU: intensive care unit; INR: International Normalized Ratio; MELD score: Model of End Stage Liver
Disease score; MODS: multiple organ dysfunction syndrome; SAPS II: Simplified Acute Physiology Score.

\section{Author details}

'Il. Medizinische Klinik, Klinikum rechts der Isar der Technischen Universität München, Ismaningerstr. 22, 81675 München, Germany. ${ }^{2}$ Institut für klinische Chemie und Pathobiochemie, Klinikum rechts der Isar der Technischen Universität München, Ismaningerstr. 22, 81675 München, Germany.

\section{Authors' contributions}

$\mathrm{BS}, \mathrm{VP}$, and GM contributed to the conception and design of the study. They were responsible for acquisition, analysis, and interpretation of data. BS drafted the manuscript. RMS and WH participated in its design and coordination and helped to draft the manuscript.

\section{Competing interests}

The authors declare that they have no competing interests.

Received: 19 January 2010 Revised: 21 April 2010

Accepted: 20 May 2010 Published: 20 May 2010

\section{References}

1. Jang $\mathbb{I K}$, Hursting MJ: When heparins promote thrombosis: review of heparin-induced thrombocytopenia. Circulation 2005, 111:2671-2683.

2. Girolami B, Prandoni P, Stefani PM, Tanduo C, Sabbion P, Eichler P, Ramon R, Baggio G, Fabris F, Girolami A: The incidence of heparininduced thrombocytopenia in hospitalized medical patients treated with subcutaneous unfractionated heparin: a prospective cohort study. Blood 2003, 101:2955-2959.

3. Greinacher A, Eichler P, Lubenow N, Kwasny H, Luz M: Heparin-induced thrombocytopenia with thromboembolic complications: meta-analysis of 2 prospective trials to assess the value of parenteral treatment with lepirudin and its therapeutic aPTT range. Blood 2000, 96:846-851.

4. Greinacher A, Volpel H, Janssens U, Hach-Wunderle V, Kemkes-Matthes B, Eichler P, Mueller-Velten HG, Potzsch B: Recombinant hirudin (lepirudin) provides safe and effective anticoagulation in patients with heparininduced thrombocytopenia: a prospective study. Circulation 1999, 99:73-80.

5. Lewis BE, Wallis DE, Berkowitz SD, Matthai WH, Fareed J, Walenga JM, Bartholomew J, Sham R, Lerner RG, Zeigler ZR, Rustagi PK, Jang IK, Rifkin SD, Moran J, Hursting MJ, Kelton JG: Argatroban anticoagulant therapy in patients with heparin-induced thrombocytopenia. Circulation 2001, 103:1838-1843.

6. Warkentin TE, Kelton JG: A 14-year study of heparin-induced thrombocytopenia. Am J Med 1996, 101:502-507.

7. Warkentin TE, Greinacher A: Heparin-induced thrombocytopenia: recognition, treatment, and prevention: the Seventh ACCP Conference on Antithrombotic and Thrombolytic Therapy. Chest 2004, 126:311S-337S.

8. Warkentin TE, Kelton JG: Delayed-onset heparin-induced thrombocytopenia and thrombosis. Ann Intern Med 2001, 135:502-506.

9. Eichler P, Budde U, Haas S, Kroll H, Loreth RM, Meyer O, Pachmann U, Potzsch B, Schabel A, Albrecht D, Greinacher A: First workshop for detection of heparin-induced antibodies: validation of the heparininduced platelet-activation test (HIPA) in comparison with a PF4/heparin ELISA. Thromb Haemost 1999, 81:625-629.

10. Hursting MJ, Alford KL, Becker JC, Brooks RL, Joffrion JL, Knappenberger GD, Kogan PW, Kogan TP, McKinney AA, Schwarz RP Jr: Novastan (brand of argatroban): a small-molecule, direct thrombin inhibitor. Semin Thromb Hemost 1997, 23:503-516.

11. Swan SK, Hursting MJ: The pharmacokinetics and pharmacodynamics of argatroban: effects of age, gender, and hepatic or renal dysfunction. Pharmacotherapy 2000, 20:318-329.

12. Guzzi LM, McCollum DA, Hursting MJ: Effect of renal function on argatroban therapy in heparin-induced thrombocytopenia. J Thromb Thrombolysis 2006, 22:169-176.

13. Reichert MG, MacGregor DA, Kincaid EH, Dolinski SY: Excessive argatroban anticoagulation for heparin-induced thrombocytopenia. Ann Pharmacother 2003, 37:652-654.

14. Williamson DR, Boulanger I, Tardif M, Albert M, Gregoire G: Argatroban dosing in intensive care patients with acute renal failure and liver dysfunction. Pharmacotherapy 2004, 24:409-414. 
15. Murray PT, Reddy BV, Grossman EJ, Hammes MS, Trevino S, Ferrell J, Tang I, Hursting MJ, Shamp TR, Swan SK: A prospective comparison of three argatroban treatment regimens during hemodialysis in end-stage renal disease. Kidney Int 2004, 66:2446-2453.

16. Link A, Girndt M, Selejan S, Mathes A, Bohm M, Rensing H: Argatroban for anticoagulation in continuous renal replacement therapy. Crit Care Med 2009, 37:105-110.

17. Schusterschitz N, Bellmann R, Stein M, Dunzendorfer S, Pechlaner C, Joannidis M: Influence of continuous veno-venous hemofiltration on argatroban clearance in a patient with septic shock. Intensive Care Med 2008, 34:1350-1351.

18. Arpino PA, Hallisey RK: Effect of renal function on the pharmacodynamics of argatroban. Ann Pharmacother 2004, 38:25-29.

19. Lewis $\mathrm{BE}$, Wallis DE, Leya F, Hursting MJ, Kelton JG: Argatroban anticoagulation in patients with heparin-induced thrombocytopenia. Arch Intern Med 2003, 163:1849-1856.

20. Gray $A$, Wallis DE, Hursting MJ, Katz E, Lewis BE: Argatroban therapy for heparin-induced thrombocytopenia in acutely ill patients. Clin Appl Thromb Hemost 2007, 13:353-361.

21. Selleng K, Warkentin TE, Greinacher A: Heparin-induced thrombocytopenia in intensive care patients. Crit Care Med 2007, 35:1165-1176.

22. Levine RL, Hursting MJ, McCollum D: Argatroban therapy in heparininduced thrombocytopenia with hepatic dysfunction. Chest 2006, 129:1167-1175.

23. Akca S, Haji-Michael P, de Mendonca A, Suter P, Levi M, Vincent JL: Time course of platelet counts in critically ill patients. Crit Care Med 2002, 30:753-756.

24. Kodityal S, Manhas AH, Udden M, Rice L: Danaparoid for heparin-induced thrombocytopenia: an analysis of treatment failures. Eur J Haematol 2003, 71:109-113.

25. Magnani HN: Heparin-induced thrombocytopenia (HIT): an overview of 230 patients treated with orgaran (Org 10172). Thromb Haemost 1993, 70:554-561.

26. Greinacher A, Janssens U, Berg G, Bock M, Kwasny H, Kemkes-Matthes B, Eichler P, Volpel H, Potzsch B, Luz M: Lepirudin (recombinant hirudin) for parenteral anticoagulation in patients with heparin-induced thrombocytopenia: Heparin-Associated Thrombocytopenia Study (HAT) investigators. Circulation 1999, 100:587-593.

27. O'Shea SI, Ortel TL, Kovalik EC: Alternative methods of anticoagulation for dialysis-dependent patients with heparin-induced thrombocytopenia. Semin Dial 2003, 16:61-67.

28. Matsuo T, Yamada T, Yamanashi T, Ryo R: Anticoagulant therapy with MD805 of a hemodialysis patient with heparin-induced thrombocytopenia. Thromb Res 1990, 58:663-666.

29. Reddy BV, Grossman EJ, Trevino SA, Hursting MJ, Murray PT: Argatroban anticoagulation in patients with heparin-induced thrombocytopenia requiring renal replacement therapy. Ann Pharmacother 2005, 39:1601-1605.

30. Tang IY, Cox DS, Patel K, Reddy BV, Nahlik L, Trevino S, Murray PT: Argatroban and renal replacement therapy in patients with heparininduced thrombocytopenia. Ann Pharmacother 2005, 39:231-236.

31. Selleng K, Selleng S, Greinacher A: Heparin-induced thrombocytopenia in intensive care patients. Semin Thromb Hemost 2008, 34:425-438.

32. Beiderlinden M, Treschan TA, Gorlinger K, Peters J: Argatroban anticoagulation in critically ill patients. Ann Pharmacother 2007, 41:749-754.

33. Krishnan V, Murray P: Pharmacologic issues in the critically ill. Clin Chest Med 2003, 24:671-688.

doi:10.1186/cc9024

Cite this article as: Saugel et al: Argatroban therapy for heparininduced thrombocytopenia in ICU patients with multiple organ dysfunction syndrome: a retrospective study. Critical Care 2010 14:R90.

\section{Submit your next manuscript to BioMed Central and take full advantage of:}

- Convenient online submission

- Thorough peer review

- No space constraints or color figure charges

- Immediate publication on acceptance

- Inclusion in PubMed, CAS, Scopus and Google Scholar

- Research which is freely available for redistribution

Submit your manuscript at www.biomedcentral.com/submit
Biomed Central 